\title{
Non-toxic low-cost heavy liquid separation in the Geological Survey of Greenland
}

\author{
Poul Schiøler
}

Density separation of mineral and sediment grains into fractions using heavy liquids traditionally employs organic compounds such as bromoform (density 2.89) and tetrabromoethane (density 2.96) which are known to be toxic even at very low concentrations (Van Haaften, 1969) and possibly carcinogenic. In addition, the separated grains are washed with organic solvents such as acetone which may be highly inflammable, and are also a health risk. In recent years, a new water soluble compound, sodium polytungstate (SPT), $3 \mathrm{Na}_{2} \mathrm{WO}_{4} \cdot 9 \mathrm{WO}_{3} \cdot \mathrm{H}_{2} \mathrm{O}$, has become available as a medium for heavy liquid separations, offering an alternative to the heavy organic liquids. Its use has been discussed by several workers (e.g. Plewinsky \& Kamp, 1984; Krukowski, 1988) in a variety of geological settings.

The present note summarises experience in GGU's palaeontological laboratory gained from working with SPT for a full year as a replacement for tetrabromoethane and bromoform in the separation of phosphatic microfossils from samples principally of Lower - Middle Cambrian age. Apart from improving the work environment by replacing high health-risk chemicals with water soluble products without known detrimental effects, SPT has proved to be both an economical and potentially efficient alternative to the organic heavy liquids.

SPT is patented, and only available from Sometu, Falkenried 4, D 1000 Berlin 33, Federal Republic of Germany.

\section{Methodology}

The white SPT powder is dissolved in distilled water following the directions given by the suppliers of the chemical. Thus, $833 \mathrm{~g}$ of powder, poured a little at a time into $155 \mathrm{~g}$ of distilled water in a $600 \mathrm{ml}$ beaker, placed on an automatic stirring device, make a $2.90 \mathrm{~g} / \mathrm{cc}$ solution. Complete homogenisation of the liquid takes about 30 minutes. Density is controlled with a hydrometer. Slight colour variation between batches of SPT solution has had no perceptible influence during separation.

Following digestion in dilute acetic acid, rock residues containing microfossils are wet sieved in six fractions (1 $\mathrm{mm}, 500 \mu \mathrm{m}, 250 \mu \mathrm{m}, 125 \mu \mathrm{m}, 75 \mu \mathrm{m}$ and $50 \mu \mathrm{m})$. Heavy liquid separation commences with the $500 \mu \mathrm{m}$ fraction and proceeds to successively finer fractions. All fractions are separated in the same separation funnel, with the result that thorough cleaning between fractions is not necessary.

In GGU's palaeontological laboratory we use a standard solution of $2.90 \mathrm{~g} / \mathrm{cc}$ for the initial separation of a sample fraction. Depending on the degree of separation of the residue, we may choose either to dilute the solution with a few millilitres of distilled water poured directly into the separation funnel, which is then shaken, or to increase the density of the solution by adding high density SPT solution $(3.10 \mathrm{~g} / \mathrm{cc})$. This high density solution is made up by heating $400 \mathrm{ml}$ of a standard solution $(2.90 \mathrm{~g} / \mathrm{cc})$ in a $600 \mathrm{ml}$ beaker in the oven at $80^{\circ} \mathrm{C}$ for approximately 7 hours, plus cooling time. Thus, solution density is readily varied from sample fraction to sample fraction, and even within the same fraction to accomplish separation.

About $25 \mathrm{ml}$ of sample residue are poured into a separation funnel containing $250 \mathrm{ml}$ of SPT solution. The funnel is rapidly rotated obliquely to its long axis in order to create a vortex that will mix the residue with the liquid. This mixing procedure is repeated two or three times during the first hour, taking care not to remix already separated heavy grains with the float fraction. In marked contrast to separation in organic heavy liquids, the presence of some moisture in the sieved residues will not cause clumping in the aqueous SPT solution. Making allowance for appropriate separation times ( 1 hour for the coarse fractions, 3 hours for the medium fractions, and up to 6 hours or longer for the $75 \mu \mathrm{m}$ and $50 \mu \mathrm{m}$ fractions), it is possible for all the material from a medium sized rock sample to be processed in two normal working days, using a single separation funnel. For convenience we run no more than four separation funnels (i.e. 4 rock samples) at a time.

The relatively high viscosity of the SPT solution prevents the use of normal laboratory filter papers for removal of sediment grains from solution, and some workers prefer commercial coffee filters on account of their more open texture and cheaper cost. In GGU, fast and efficient filtration is accomplished by filtration through pieces of nylon filter cloth which can be used repeatedly for separations. We use the following mask sizes: $125 \mu \mathrm{m}$ for the 500 and $250 \mu \mathrm{m}$ fraction; $50 \mu \mathrm{m}$ for the $125 \mu \mathrm{m}$ fraction; and $20 \mu \mathrm{m}$ for the 75 and $50 \mu \mathrm{m}$ 

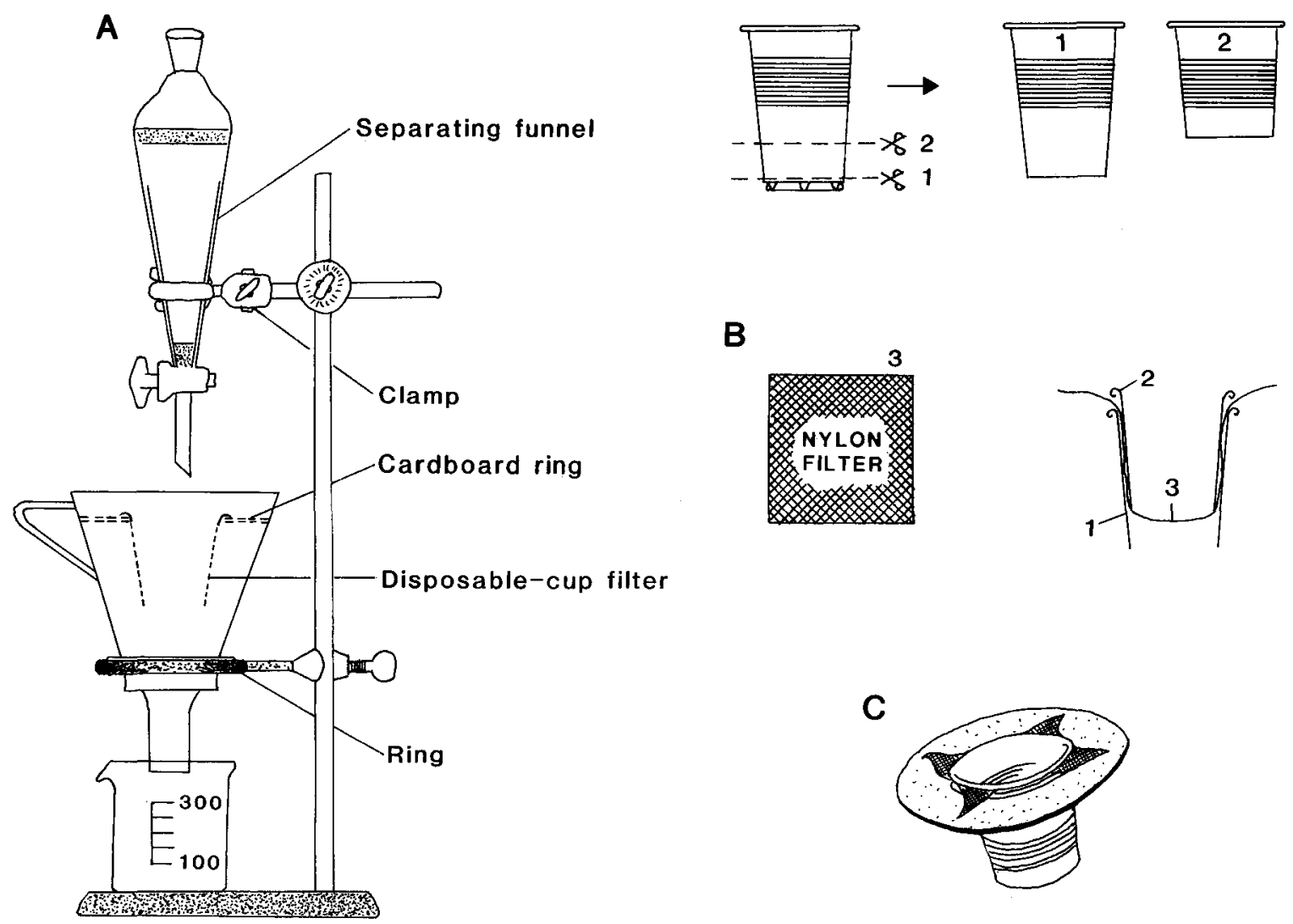

B

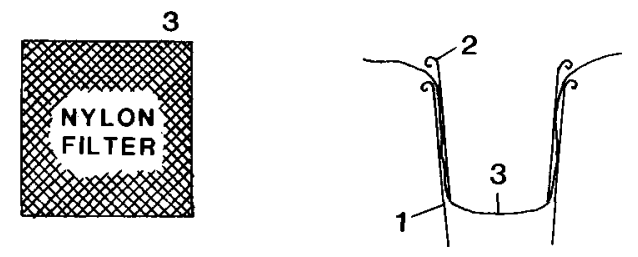

Fig. 1. The filter device is made in the following way: (A) a coffee filter funnel no. 3 is snapped into a ring mounted on a stand, with a $400 \mathrm{ml}$ beaker placed under it; (B) a $15 \times 15 \mathrm{~cm}$ piece of nylon filter cloth (e.g. Scrynel HD) is placed between 2 disposable plastic coffee cups from which the bottoms have been cut away; $(C)$ the coffee cup filter unit is suspended in the coffee filter funnel by means of a cardboard or plastic-ring inserted in the filter funnel.

fraction. Used filters are washed in household detergent, then in distilled water, and finally dried for re-use.

After the separation of a sample fraction is completed, the fraction is tapped into a filter unit, described in fig. 1, and the filtered heavy liquid (high density solution) is saved for re-use. The heavy fraction in the filter-unit is washed with distilled water on the filter, and the resultant washings (low density solution) are saved for regeneration. The same washing procedure is followed for the float fraction. After the completion of the first separation, about $240 \mathrm{ml}$ of re-usable high density solution and some $100 \mathrm{ml}$ of low density solution remain. Following the separation of the last and finest fraction of a rock sample, the high density solution in most cases has become clouded and dirty due to the constant re-use. The amount of the low density solution (washings) has grown to approximately $500 \mathrm{ml}$ per funnel. These solutions can be processed to recover SPT of the initial density and clarity by the process described below.

\section{Regeneration}

Recovery of the initial solution is accomplished by the following procedure:

1. About $400 \mathrm{ml}$ of the cloudy high density solution are decanted into a tall $600 \mathrm{ml}$ beaker and diluted with distilled water to a density of about $2.2 \mathrm{~g} / \mathrm{cc}$. The solution is placed in an oven at $80^{\circ} \mathrm{C}$. The following day, or after approximately 16 hours, the density of the solution has risen to approximately $2.6 \mathrm{~g} / \mathrm{cc}$, and the suspended fine sediment has settled to the bottom. The transparent liquid above is decanted into another beaker and allowed to evaporate in the oven to the desired density.

2. About 1 litre of the low density solution (washings) is decanted into two tall $600 \mathrm{ml}$ beakers and allowed to evaporate in the hot oven together with the diluted high density solution, following the above procedure. Wet sediment from the beaker that contained the diluted high density solution is often washed into the low den- 
sity solution for recovery of the small amount of SPT still adhering to the settled sediment.

\section{The dolomite problem}

Krukowski (1988) has stressed the need to avoid contamination by calcium ions since these form a white precipitate of calcium polytungstate. Normally calcium is removed from samples by the action of acetic acid prior to separation, but calcium ions may be present in local water supplies used for washing and sieving samples. Thus, all samples are routinely washed in distilled water after sieving, prior to separation in SPT. All relevant laboratory equipment is also rinsed with distilled water after use.

Sample residues containing large amounts of dolomite present a special problem. Calcium ions from the dolomite-rich residue under separation diffuse into the SPT solution, forming a white precipitate of calcium polytungstate (cf. Krukowski, 1988). Luckily, the rate of formation of the precipitate is very slow at room temperature. Within the separation time available in a normal working day, no appreciable quantity of precipitate is formed. If, however, the sample is left overnight, a silky white precipitate will cover the heavy fraction at the bottom of the separation funnel the next morning. The white precipitate is only weakly soluble in water but, due to the small size of the calcium polytungstate crystallites formed, it is possible to dispose of most of them by rinsing the heavy fraction thoroughly with water, even on a $20 \mu \mathrm{m}$ nylon filter. Polluted solutions can be cleansed of the crystallites by dilution, which causes the crystallites to settle, and subsequent decantation of the pure SPT solution. Heating in an oven after dilution causes the crystallites to weld together, facilitating decantation.

\section{Observations}

This article is written on the basis of 382 heavy liquid separations. Of the initial $6500 \mathrm{~g}$ of powder brought into solution, $3068 \mathrm{~g}$ were still in use at the time of writing. This means that $9 \mathrm{~g}$ of powder on average were lost per separation. For a standard $250 \mathrm{ml}$ separation this amount is equivalent to the loss of about 1.5 per cent of the separation liquid ( $9 \mathrm{~g}$ of SPT powder yield $10.8 \mathrm{~g}$ of solution with density $2.90 \mathrm{~g} / \mathrm{cc}$ ). Thus, there is a recovery rate of about 98.5 per cent of the SPT solution in use.

SPT is approximately twice as expensive to buy as tetrabromoethane. Use of the latter, however, requires large quantitites of acetone to clean samples after separation, while only water is employed to wash samples separated in SPT. In the context of our small laboratory, regeneration of acetone washings to produce reusable tetrabromoethane and acetone has not proved economical, resulting in a higher loss of tetrabromoethane per sample relative to SPT, and a total loss of the acetone used for washing (more than 1 litre per sample). Despite its high acquisition cost SPT is therefore less expensive to use than tetrabromoethane.

\section{Conclusions}

Few of the Cambrian micropalaeontological samples processed in GGU's palaeontological laboratory respond similarly to heavy liquid separation due to considerable variation in their derivation and lithological composition. Use of SPT solution provides a flexible separation medium which can be easily adjusted to the requirements of particular samples during the separation procedure itself. Apart from reducing serious health hazards by replacing toxic organic compounds, SPT is economical in use, requiring only water for washing separated samples. Moist samples from the sieving process can also be separated without thorough drying. Plastic laboratory ware can be used as a replacement for expensive and vulnerable glass.

The process, however, is not without disadvantages which might prove important in separation procedures in other laboratories with different basic needs. The high viscosity of SPT in the uppermost part of its density range results in longer separation times relative to tetrabromoethane. Regeneration of SPT is relatively time consuming. However, regeneration is now possible in our laboratory, whereas regeneration of the tetrabromoethane and acetone previously employed was not feasible. Gravity filtration in standard papers is not possible, but the use of nylon-mesh filters provides unsurpassed filtration.

Acknowledgements. John S. Peel is thanked for helpful comments and for improving the English of the manuscript.

\section{References}

Krukowski, S. T. 1988: Sodium metatungstate: a new heavymineral separation medium for the extraction of conodonts from insoluble residues. J. Paleontol. 62, 314-316.

Plewinsky, B. \& Kamp, R. 1984: Sodium metatungstate, a new medium for binary and ternary density centrifugation. Makromolekulare Chemie 185, 1429-1439.

Van Haaften, A. B. 1969: Acute tetrabromoethane (acetylene tetrabromide) intoxication in man. J. Am. Industr. Hygiene Assoc. 30, 251-256.

P. S., Grønlands Geologiske Undersøgelse, $\emptyset$ ster Voldgade 10, DK-1350 København $K$, Danmark. 